\title{
Effect of Growth Time on the Structural, Optical and Electrical Properties of the 1\%Fe doped TiO2 p-type Synthesized by Hydrothermal Technique
}

\author{
Sattar J. Hashim (iD) a*, Odai N. Salman ${ }^{\text {b }}$, Khaleel I. Hassoon ${ }^{\text {c }}$ \\ a Department of Applied Sciences, University of Technology, Baghdad, Iraq, sattarjabir314@gmail.com \\ b Department of Applied Sciences, University of Technology, Baghdad, Iraq, micro_ud@yahoo.com \\ c Department of Applied Sciences, University of Technology, Baghdad, Iraq, kihassoun@yahoo.com \\ *Corresponding author.
}

\begin{tabular}{|c|c|}
\hline Submitted: $20 / 10 / 2020$ & Published: $25 / 07 / 2021$ \\
\hline K E Y W O R D S & A B S T R A C T \\
\hline $\begin{array}{l}\text { Hydrothermal } \\
\text { Technique, Titanium } \\
\text { dioxide, p-type, Growth } \\
\text { time and vertical aligned } \\
\text { nanorods }\end{array}$ & $\begin{array}{l}\text { In this work, a hydrothermal technique is employed to prepare titanium } \\
\text { dioxide films on fluorine-doped tin oxide (FTO) substrates. A low-cost } \\
\text { homemade autoclave was used to fabricate iron-doped -TiO2 films (lat. } \\
\text { \%Fe) at different reaction times from } 1 \text { to } 4 \text { hours. X-ray diffraction (XRD) } \\
\text { patterns showed that the predominant phase is rutile (R-TiO2) with peaks } \\
\text { at (101), (002), and (112). The XRD results showed that with increasing } \\
\text { reaction time the peaks become sharper and narrowed. The images of the } \\
\text { field emission scanning electron microscope (FESEM) showed that with } \\
\text { increasing reaction time the films appeared to have vertically aligned TiO2 } \\
\text { nanorods. The atomic force microscope (AFM) results illustrated that } \\
\text { surface roughness and the root means square was decreased with } \\
\text { increasing the reaction time. UV-visible spectroscopy analysis revealed } \\
\text { that the energy bandgap value (Eg) decreased with reaction time up to } 3 \\
\text { hours. Urbach energy for the grown films was found to be decreased with } \\
\text { increasing growth time. The electrical measurements indicated that all } \\
\text { TiO2 films had p-type conductivity. }\end{array}$ \\
\hline
\end{tabular}

\footnotetext{
How to cite this article: S. J. Hashim, O. N.Salman, and K. I. Hassoon, "Effect of Growth Time on the Structural, Optical and Electrical Properties of the 1\%Fe doped TiO2 p-type Synthesized by Hydrothermal Technique," Engineering and Technology Journal, Vol. 39, No. 07, pp. 1133-1143, 2021.

DOI: https://doi.org/10.30684/etj.v39i7.1874

This is an open access article under the CC BY 4.0 license http://creativecommons.org/licenses/by/4.0
}

\section{INTRODUCTION}

Titanium dioxide is one of the important semiconductors that have a wide energy bandgap (about $3.1 \mathrm{eV}$ ). In most cases, $\mathrm{TiO}_{2}$ has n-type conductivity [1]. It has three structures, namely, anatase, rutile, and brookite. The rutile phase in particular exhibits high hardness and refractive index with good transparency in the visible region. These desired properties increased the importance of this material for optoelectronic applications such as UV detectors [2], solar cells [3], and light-emitting diodes [4]. The optical and structural properties of $\mathrm{TiO}_{2}$ Nano Rods (NRs) have attracted considerable attention, because of their large surface to volume ratio which enhances the material 
absorption increases the mean free path of the carriers. However, its wide bandgap energy results in low light-harvesting efficiency of sunlight because only the ultraviolet light has sufficient energy to support the electron transition from the valence band to the conduction band and this blemish reduces its practical importance in the field of solar cells. Therefore, there is a need to develop new-versions of $\mathrm{TiO}_{2}$ with enhanced performance under visible light irradiation. Doping with certain elements is a promising solution to this problem since it can reduce the bandgap and hence extend its spectral response in the visible region. Moreover, the bandgap is proved to be a function of preparation conditions. $[5,6]$. In this work, we study the effect of growth time on the structural, optical, and electrical properties of $\mathrm{TiO}_{2}$ prepared by the hydrothermal method.

\section{EXPERIMENTAL DETAILS}

In the present paper, FTO-glass (TEC 8 with $600 \mathrm{~nm}$ in thickness from DyeSol Company) is utilized as substrates. The substrates are ultrasonically cleaned for 15 minutes using acetone, ethanol, and double-distilled water (purchased from a local store). Then the samples are dried in air and placed at an angle of $45^{\circ}$ inside a sealed container made of Teflon. A volume of $\mathrm{HCl}$ acid $(37 \%$ Sigma-Aldrich) is dissolved in $20 \mathrm{~mL}$ of double-distilled $\mathrm{H}_{2} \mathrm{O}$ and is thoroughly mixed using a magnetic stirrer for $5 \mathrm{~min}$. After that, $(1.022 \mathrm{~mL})$ of titanium butoxide provided by Sigma-Aldrich is blended with the solution and kept for another 5 min. The doping of $\mathrm{TiO}_{2}$ was implemented by adding $\mathrm{Fe}\left(\mathrm{NO}_{3}\right) 9 \mathrm{H}_{2} \mathrm{O}$ (from HiMedia Laboratories Pvt. Ltd) as a precursor of Fe to maintain the atomic ratio (at.) of $\mathrm{Fe} / \mathrm{Ti}(1 \mathrm{at} \%)$. The solution was stirred again for $90 \mathrm{~min}$. At first, the mixture was clear and transparent but after adding the Iron nitrate nonahydrate it became near to Green. $20 \mathrm{~mL}$ of the mixture is charged to a homemade stainless-steel autoclave $(30 \mathrm{~mL})$. A schematic diagram for the autoclave is presented in [7]. The autoclave was put inside an electric oven. The oven was preheated at $180^{\circ} \mathrm{C}$ ( $\pm 3 \mathrm{ramp}$ rate) for different periods of preparation time $(1,2,3$, and 4$)$ hours. After this time, the autoclave was removed from the oven and slowly cooled down under a stream of water and the FTO glass substrate was brought out and rinsed with distilled water many times to remove any extra reactants, finally, the samples were dried in air at RT for $15 \mathrm{~min}$. It is worth noting that the film prepared at 4 hours was peel off from the FTO substrate as presented in Figure 1, so it was excluded from all measurements. The prepared samples were characterized by XRD of $\mathrm{Cu} K \alpha(\lambda=1.5405 \AA)$ with scan rate $8(\mathrm{deg} / \mathrm{min})$, and the scanning range was 20 to $75^{\circ}$ in step-size $0.02^{\circ}$. The $\mathrm{x}$-ray voltage was $40 \mathrm{kV}$, and the current was $30 \mathrm{~mA}$ (College of Education Ibn al-Haytham). The FESEM, which is supported with Energy Dispersive Spectroscopy (EDS), was used to view the structure of the $1 \% \mathrm{Fe}^{-\mathrm{TiO}_{2}}$ nanorods (Razi Applied Science Foundation - Tehran, Iran). The UV-Vis spectroscopy (Shimadzu UV-1900i in our Nanoscale laboratory) visible spectrophotometer was used to investigate the optical properties of the films in the range $(370-1100 \mathrm{~nm})$ at room temperature. Hall effect measurements were done (in our Electromechanical Lab) by employing (Lybold) system with magnetic field $\mathrm{B}=0.025 \mathrm{~T}$ to calculate the Hall coefficients $\left(\mathrm{R}_{\mathrm{H}}\right)$, carrier concentrations $(\mathrm{n})$, and the mobility $(\mu)$ of the films. Measuring the electrical resistance of the films was carried out in the Photoelectric Lab through the DC measurements directly, with temperature ranging from $55^{\circ} \mathrm{C}$ up to $125^{\circ} \mathrm{C}$.

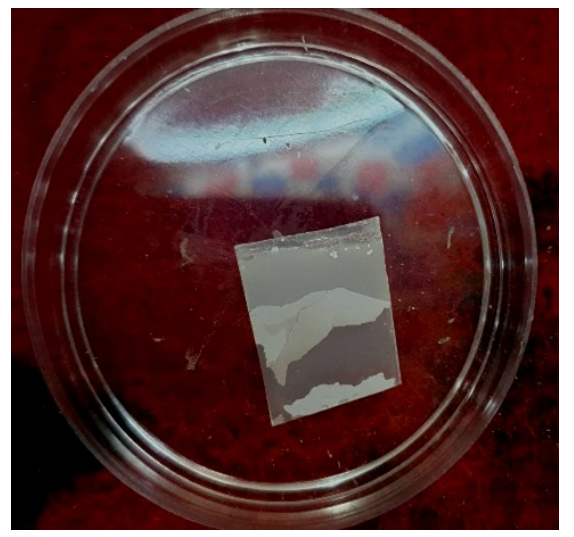

Figure 1: Picture of the peel-off films of $1 \% \mathrm{Fe}-\mathrm{TiO}_{2}$ prepared at 4 hours by hydrothermal technique 


\section{RESULTS AND DISCUSSIONS}

In this work, the XRD diffraction technique is used to characterize the phase and crystallinity of $1 \%$ Fe-doped $\mathrm{TiO}_{2}$ nanorods with different reaction time $(1,2$, and 3 hours) as illustrated in Figure 2 deposited by the hydrothermal deposition method on FTO glass at $180^{\circ} \mathrm{C}$ in $20 \mathrm{ml}$ of double-distilled $\mathrm{H}_{2} \mathrm{O}, 20 \mathrm{ml}$ of hydrochloric acid, $0.0121 \mathrm{mg}$ of iron nitrate nonahydrate and $1.022 \mathrm{ml}$ of Titanium butoxide. The XRD patterns display that these films deposited on FTO substrates are tetragonal rutile titanium dioxide $\left(\mathrm{R}-\mathrm{TiO}_{2}\right)$ type. The locations of the peaks agree with (JCPDS 89-4920 card). No other peaks related to different phases of $\mathrm{TiO}_{2}$ have been identified. Remarkably, no clear appearance of Fe diffraction peaks, due to the very low concentration of Fe used. In Figure 2, the stars represent the diffraction peaks for FTO substrate and R represents Rutile phase of $\mathrm{TiO}_{2}$. The diffraction pattern of $\mathrm{TiO}_{2} \mathrm{NRs}$ for growth time (1 hour) shows two small peaks of $\mathrm{R}-\mathrm{TiO}_{2}$ at (101) and (002) corresponding to $2 \theta=35.946^{\circ}$ and $62.673^{\circ}$ respectively. The $\mathrm{TiO}_{2}$ films synthesized with higher growth time (2 hours) reveals stronger peaks of rutile corresponding to the planes (101), (002) and (112) for $2 \theta=\left(35.946^{\circ}, 62.673^{\circ}\right.$, and $\left.69.681^{\circ}\right)$ respectively. The film prepared with a development time of 3 hours we noted that the first two peaks increased in intensity noting that the (002) is the highest intensity peaks of the deposited film with this reaction time with no affection on the intensity of (112) peak which was very weak. The effect of reaction time on the $1 \% \mathrm{Fe}$ doped $\mathrm{TiO}_{2}$ film structure parameters is tabled in Table I. It is worthwhile to mention that the main reason that makes the hydrothermal method producing $\mathrm{R}$ phase rather than other phases of $\mathrm{TiO}_{2}$ is that $\mathrm{FTO}$ and $\mathrm{R}-\mathrm{TiO}_{2}$ have a low lattice mismatch parameter [8].

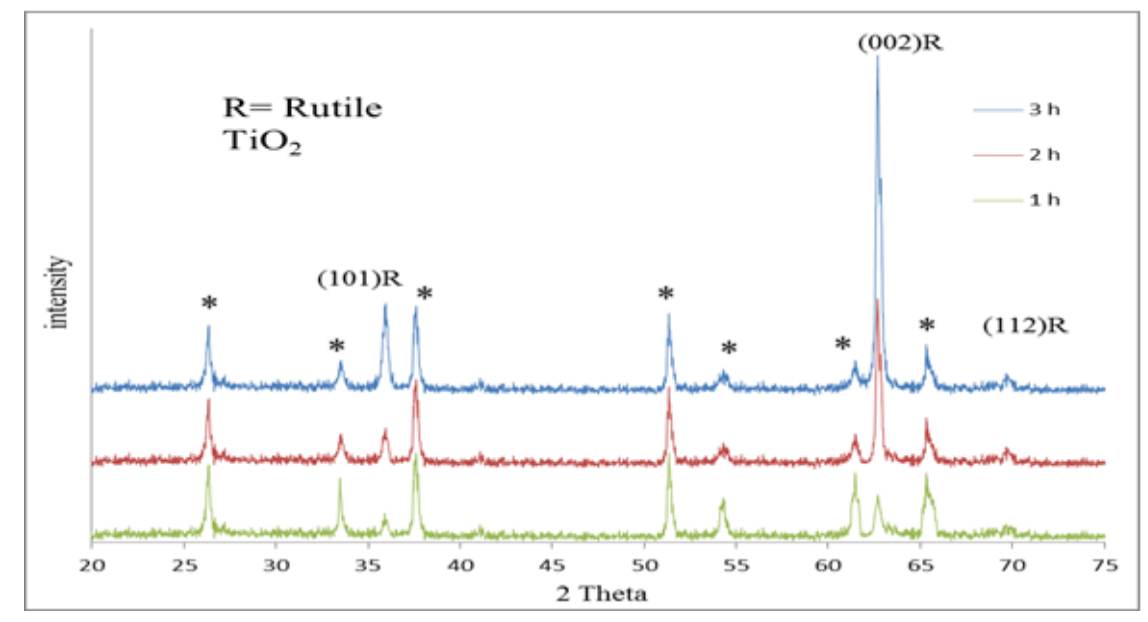

Figure 2: XRD-diffractograms for the $1 \% \mathrm{Fe}$ doped $\mathrm{R}-\mathrm{TiO}_{2}$ samples with different reaction times prepared on the FTO-glass substrates by the hydrothermal technique.

TABLE I: Effect of reaction time on the XRD parameters for $1 \% \mathrm{Fe}-\mathrm{TiO}_{2}$ nanorods synthesized at different reaction times

\begin{tabular}{|c|c|c|c|c|c|c|c|}
\hline $\begin{array}{c}\text { Reaction } \\
\text { time of } \\
1 \% \text { Fe-TiO }\end{array}$ & $\begin{array}{c}2 \theta \\
(\operatorname{deg})\end{array}$ & hkl & $\begin{array}{c}\text { d- } \\
\text { spacing } \\
(\AA)\end{array}$ & $\begin{array}{c}\text { FWHM } \\
\beta \\
\text { (rad) }\end{array}$ & $\begin{array}{c}D \\
(\mathrm{~nm})\end{array}$ & $\begin{array}{r}(S) * 10^{-3} \\
\left(\text { lines } / \mathbf{n m}^{2}\right)\end{array}$ & $\varepsilon_{*} 10^{-3}$ \\
\hline \multirow{3}{*}{ 1hour } & 35.964 & 101 & 2.49514 & 0.49890 & 16.754 & 0.00356 & 0.706 \\
\hline & 62.830 & 002 & 1.47783 & 0.34750 & 26.809 & 0.00139 & 0.926 \\
\hline & 35.979 & 101 & 2.49367 & 0.37290 & 22.417 & 0.00198 & 0.528 \\
\hline \multirow[t]{3}{*}{ 2hours } & 62.747 & 002 & 1.47959 & 0.30790 & 30.244 & 0.00109 & 0.819 \\
\hline & 69.674 & 112 & 1.34730 & 0.32210 & 30.073 & 0.00110 & 0.978 \\
\hline & 35.946 & 101 & 2.49591 & 0.34000 & 24.584 & 0.00165 & 0.481 \\
\hline \multirow[t]{2}{*}{ 3hours } & 62.696 & 002 & 1.48066 & 0.22890 & 40.671 & 0.00060 & 0.608 \\
\hline & 69.674 & 112 & 1.34845 & 0.29330 & 33.026 & 0.00091 & 0.890 \\
\hline
\end{tabular}

Figure 3 depict the top and cross cross-sectional views of $1 \% \mathrm{Fe}$-doped $\mathrm{TiO}_{2}$ films synthesized with different reaction time (1, 2 and 3 hours), respectively at $180^{\circ} \mathrm{C}$. The images illustrate that the $1 \% \mathrm{~F}$-doped $\mathrm{TiO}_{2}$ films deposited on the FTO substrate are vertically aligned nanorods with a tetragonal shape and square top facet. It can be seen that the whole surface of the FTO-glass substrate was evenly covered with $\mathrm{TiO}_{2}$ nanorods. It is worthwhile to mention that with increasing reaction 
time both the length and diameter of the nanorods increased as shown in Table II. With one hour of biofilm development, the length of the nanorods is about $0.87 \mu \mathrm{m}$ and the average diameter about 50 $\mathrm{nm}$. The low reaction time and immature termination of growth results in a small growth of $\mathrm{TiO}_{2}$ nanorods. When the establishment time for the film increases to two hours, the diameters of the NRs increase to $90 \mathrm{~nm}$. The lengths of the NRs were also found to enhance to $2.4 \mu \mathrm{m}$ with preferred vertical alignment. And it becomes about $4.1 \mu \mathrm{m}$ in length and $150 \mathrm{~nm}$ in average diameter with three hours of reaction time. Increasing the reaction time for three hours resulted in well grow and highly aligned $\mathrm{TiO}_{2}$ nanorods. So that, it can be concluded that both the length and diameter of the nanorods of the $1 \% \mathrm{Fe}-\mathrm{TiO}_{2}$ increase with the increasing reaction time [9]. When the length of the nanorods increases, it will cause to increasing the surface area and that can be used in several applications such as solar cell or gas sensing.

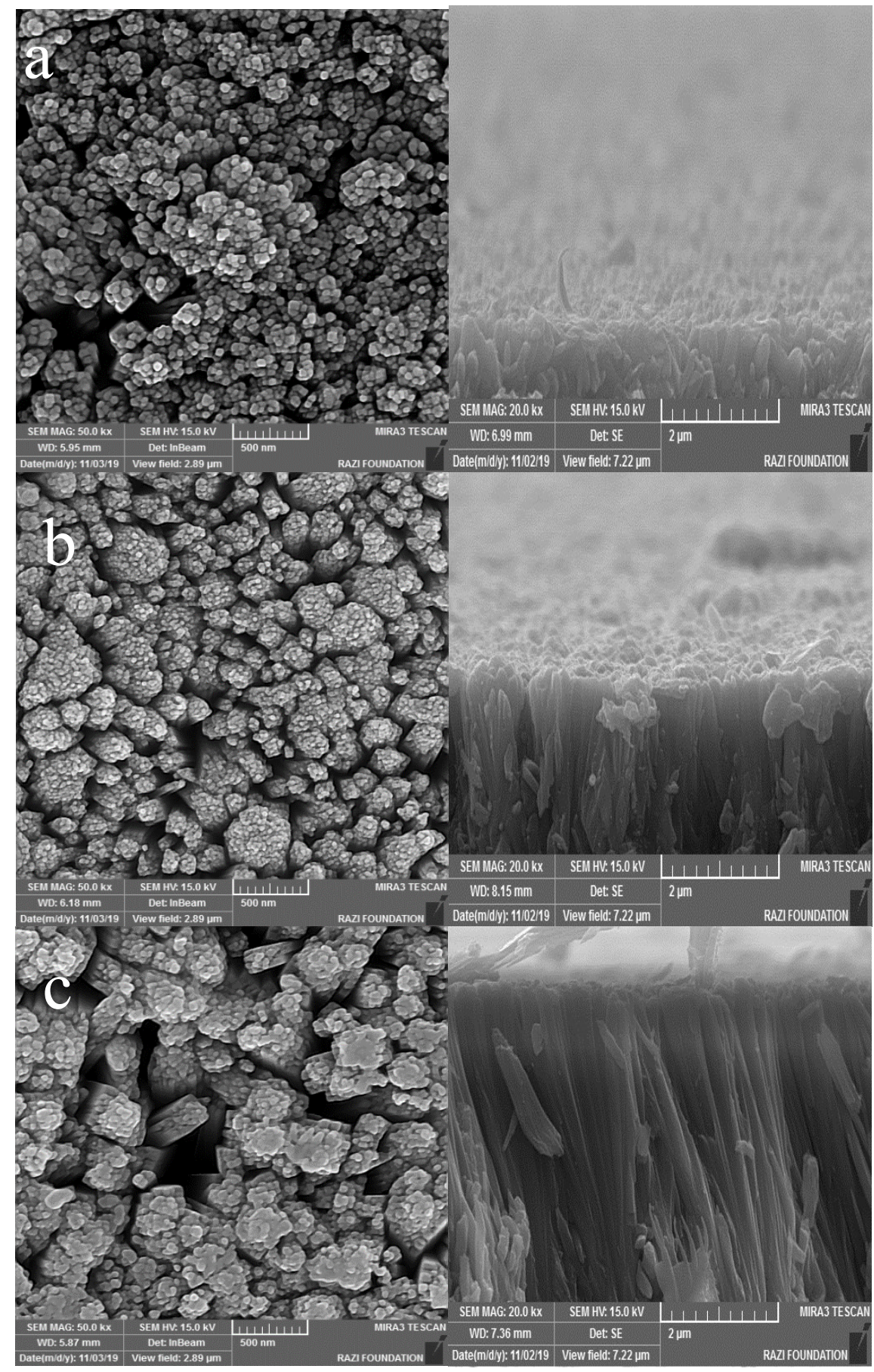

Figure 3: Pictures of FESEM of top and its cross section view on the right for the $1 \% \mathrm{Fe}^{-\mathrm{TiO}_{2}}$ for different reaction time (a) 1 hour, (b) 2 hours and (c) 3 hours, respectively 
TABLE II: morphologies properties of the $1 \% \mathrm{Fe}^{-\mathrm{TiO}_{2}}$ nanorods samples extracted from the FESEM measurements prepared at different reaction time

\begin{tabular}{ccc}
\hline \hline Preparation time (hours) & Length $(\mathbf{n m})$ & Ava. Diameter $(\mathbf{n m})$ \\
\hline 1 & 0.87 & 50 \\
2 & 2.4 & 95 \\
3 & 4.1 & 150 \\
\hline
\end{tabular}
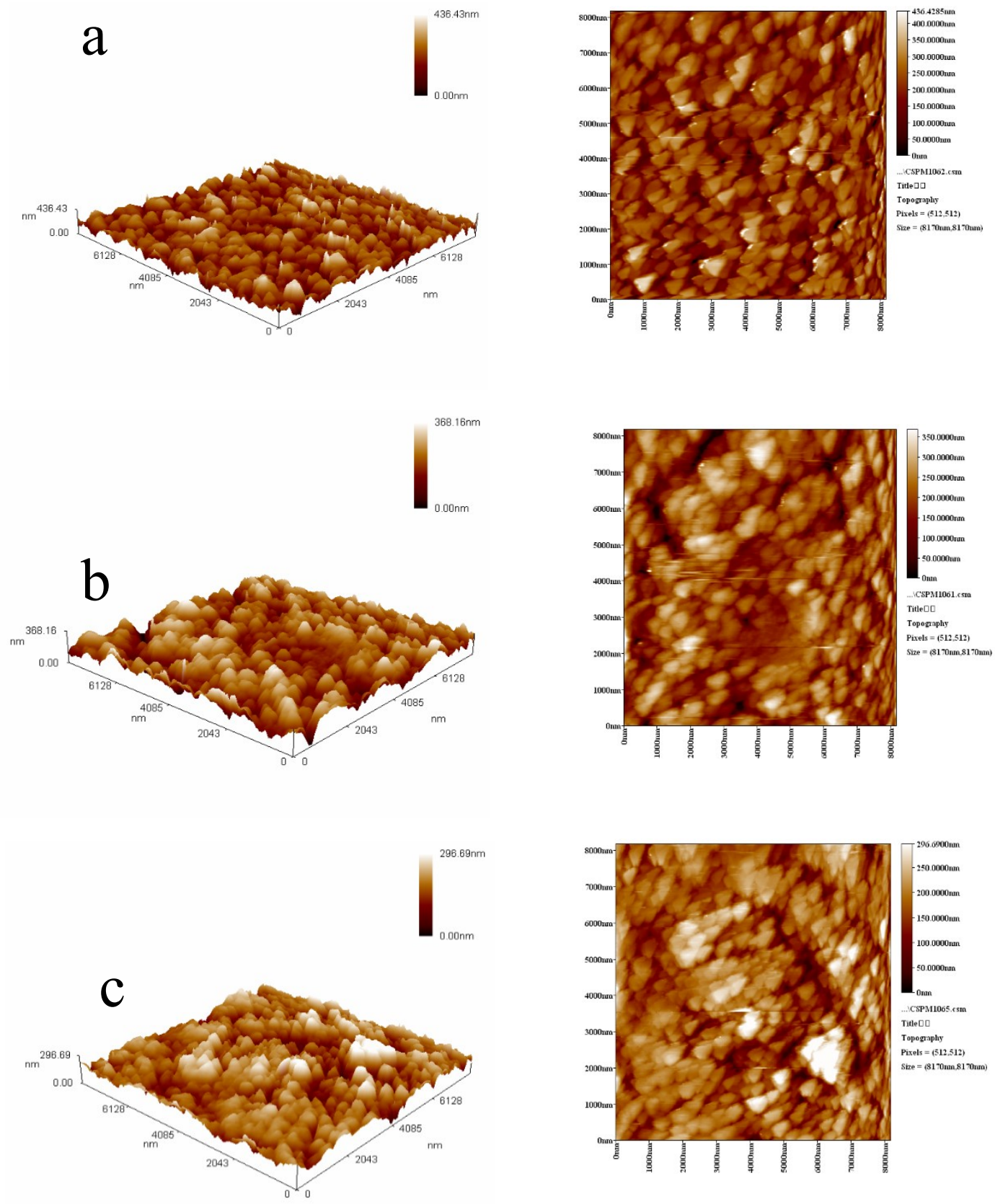

Figure 4: AFM images of three and with its two dimensions on the right of the p-type $1 \% \mathrm{Fe}-\mathrm{TiO}_{2}$ nanorods films prepared at (a) 1 hour, (b) 2 hours, and (c) 3 hours.

Atomic force microscope (AFM) was used to characterize the topography and surface roughness of the $1 \% \mathrm{Fe}-\mathrm{TiO}_{2} \mathrm{NRs}$ films grown at different duration times. Figure 4 shows the typical three - and tow dimensional AFM images of $1 \% \mathrm{Fe}-\mathrm{TiO}_{2}$ nanorods films. An obvious reduction and a lower film roughness could be achieved as the reaction time increases up to 3 hours, and also the root means square is found to decrease as increasing the preparation time of the samples, Table III illustrates these results. The results reveal a homogenous and crack-free surface which is convenient 
for optoelectronic applications. The films are constituted by round cylindrical shapes NRs packed together with a rather regular size distribution. Furthermore, it can be seen empty spaces are between these NRs.

TABLE III: $\quad$ The average roughness and root mean square of the $1 \% \mathrm{Fe}-\mathrm{TiO}_{2}$ films prepared at different reaction time

\begin{tabular}{ccc}
\hline \hline growth time (hours) & Average roughness (nm) & Root mean square (nm) \\
\hline 1 & 48.9 & 62 \\
2 & 45.9 & 57.9 \\
3 & 37.1 & 47.6 \\
\hline
\end{tabular}

Optical Properties depend on the film morphology, film thickness, chemical and nature of nanostructure of the films, also the intrinsic defects and the extrinsic impurities. In particular, the extrinsic impurities can give rise to specific properties of $\mathrm{TiO}$, so that many research works are introducing extrinsic impurities into the $\mathrm{TiO} 2$ structure to enhance the optical properties of the material. In this work, we concentrate on the study of the influence of different growth times on optical properties of the $1 \% \mathrm{Fe}-\mathrm{TiO} 2 \mathrm{p}$-type films.

Figure 5 illustrate the transmittance spectra of the 1 at $\% \mathrm{Fe}$ doped $\mathrm{TiO} 2$ for the samples synthesized at different growth time (1,2 and 3 hours) by hydrothermal technique on the FTO-glass substrate. The reaction time determines the deposited film thickness, which in turn is a function of the optical transmittance, as the film thickness increased the transmittance decreased due to increasing the length and diameter of the nanorods (light scattering effects). As revealed in the figure the transmittance was increasing as the wavelength increased, the lowest optical transmittance was for the sample synthesized with 3 hours growth time, while the highest optical transmittance was got for the sample hydrothermally grown at 1-hour, identical results were found by J. Xi et al. [10].

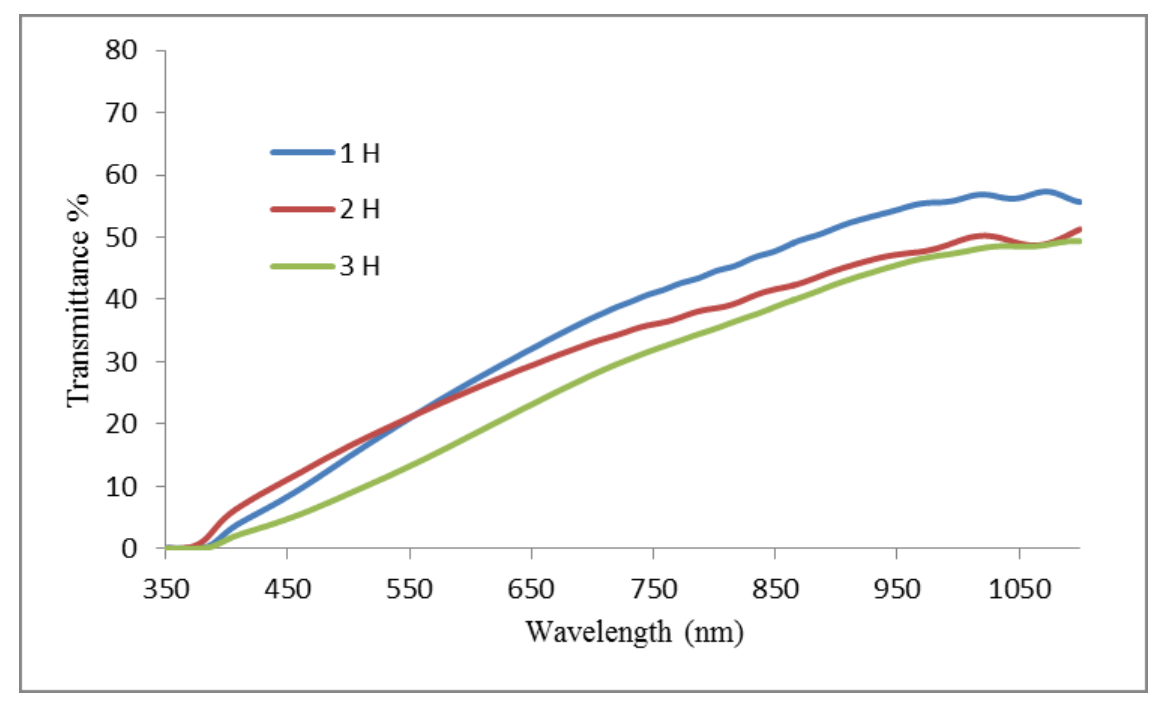

Figure 5: the transmittance spectra of the $1 \% \mathrm{Fe}-\mathrm{TiO}_{2}$ films prepared at different growth times $(1,2$, and 3 hours)

It is clear that from Figure 6 which illustrate the absorption coefficient of 1at \% Fe doped $\mathrm{TiO}_{2}$ for the samples synthesized at different reaction time (1,2 and 3 hours), the absorption coefficient threshold begun at the ultraviolet wavelength (i.e. $375 \mathrm{~nm}$ ). It was obvious that the nanorods films have the high absorption coefficient at a short wavelength ranging from $(375-450$ $\mathrm{nm}$ ) for all samples prepared, the films sharply increasing in the UV range, and then decreased gradually at the long-wavelength ranging $(500-1100 \mathrm{~nm})$ because it was inversely proportional to the transmittance. And from the other side of the view that the augmentation of the agent time of the samples leads to deposited thicker films (increasing the length and diameter of the nanorods), and there at the absorption coefficient of the film will be increased, this was confirmed with another work [10]. 


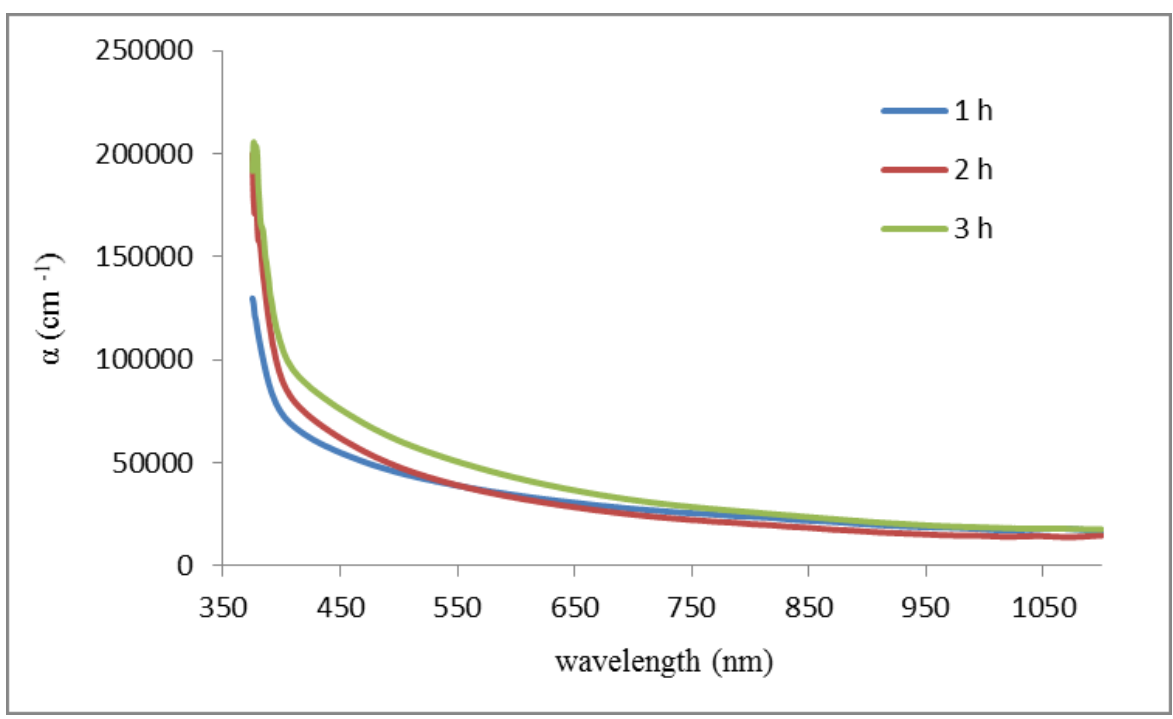

Figure 6: The optical absorption coefficient vs. the wavelength of $1 \% \mathrm{Fe}-\mathrm{TiO}_{2} \mathrm{NRs}$ deposited on FTO-glass substrate at different reaction times $(1,2$, and 3 hours)

It is well known that the titanium oxide is a direct bandgap so that the optical bandgap of the films can be estimated from Figure 7 by plotting $(\mathrm{h} v)$ in $\mathrm{eV}$ unit as a function of $(\alpha \mathrm{h} v)^{2}$, then a straight line near the absorption edge is drawing and the extrapolation of this straight line to $(\alpha h v)^{2}=0$ gives the amount of the direct bandgap of the films. The figure confirms the direct bandgap of R$\mathrm{TiO}_{2}$, and also reveals the estimated optical bandgap, the band gap was found to be $3.35 \mathrm{eV}$ for 1 hour, $3.2 \mathrm{eV}$ for 2 hours, and $3.1 \mathrm{eV}$ for 3 hours. Notice that the optical band gap decreased from (3.35 to 3.1 ) eV with an increase of preparation time from 1 to 3 hours. This result was attributed to the increase of rod diameter with increasing reaction time and thus suggesting the quantum confinement was less at higher reaction time. In all preparation conditions, the energy bandgap is found to be greater than the bulk value and this is thought to be due to quantum confinement [11].

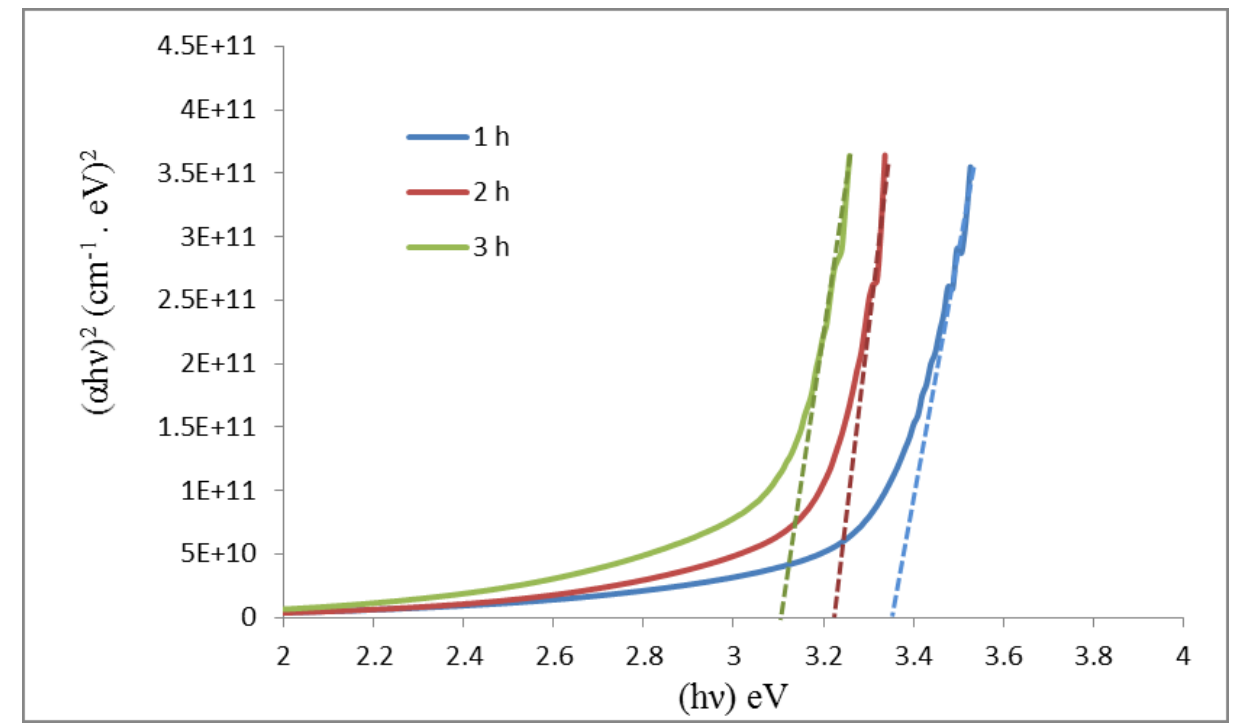

Figure 7: The estimated optical bandgap from plotting (ahv)2 as a function of photon energy derived from the transmittance spectra for the sample prepared at different reaction times $(1,2$, and 3 hours)

Urbach energy tails $(\mathrm{Eu})$ were calculated from the UV-visible measurements by plotting $\ln (\alpha)$ against $\mathrm{h} v(\mathrm{eV})$, and added a liner trendline equation into the chart, the inverse of the $\mathrm{x}$ coefficient represents the Urbach energy tails $(\mathrm{Eu})$ as performed in the Figure 8. The (Eu) tails also known as the width of the extended states underneath the conduction band. The results illustrate that the Eu decreased with increasing the reaction time from 1 to 3 hours, the results are tabulated in Table IV. 


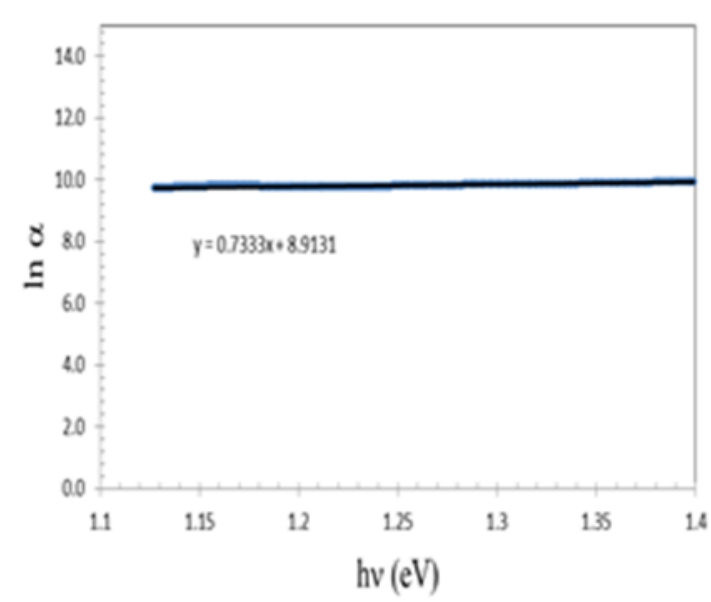

a

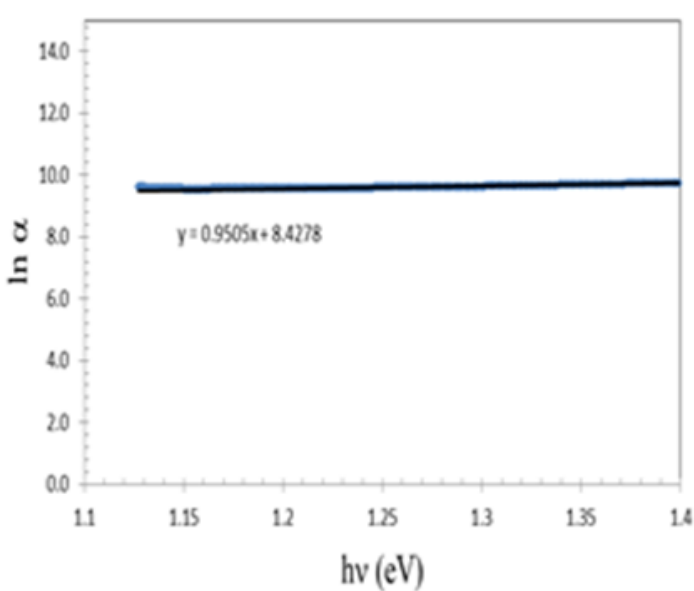

b

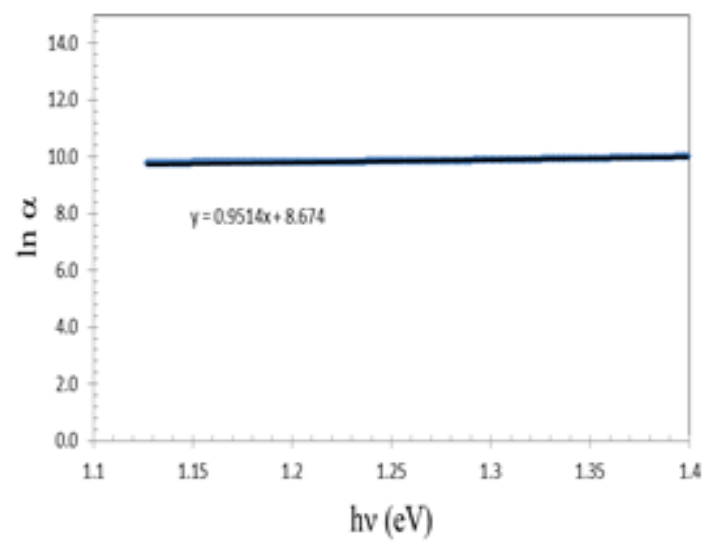

c

Figure 8: Urbach energy gap $\mathrm{E}_{\mathrm{u}}$ for the $1 \% \mathrm{Fe}$-doped $\mathrm{TiO}_{2}$ (a) 1 , (b) 2 and (c) 3 hours

TABLE IV:Energies band gap and Urbach of the samples by the UV-visible measurements

\begin{tabular}{ccc}
\hline \hline Reaction time (hour) & $\mathbf{E}_{\mathbf{g}}(\mathbf{e V})$ & $\mathbf{E}_{\mathbf{u}}(\mathbf{e V})$ \\
\hline 1 & 3.35 & 1.363698 \\
2 & 3.23 & 1.052078 \\
3 & 3.1 & 1.051083 \\
\hline
\end{tabular}

Hall measurements show that the 0.1 at $\% \mathrm{Fe}-\mathrm{TiO}_{2}$ has p-type conductivity for the whole synthesized films. Figure (9-a) depicts the Hall mobility and carrier concentration as a function of the preparation time. The electrical conductivity of the films increases from 798 to $1965\left(\Omega^{-1} . \mathrm{cm}^{-1}\right)$ with increasing the preparation time from 1 to 3 hours, respectively. As shown in Figure (9-b) 

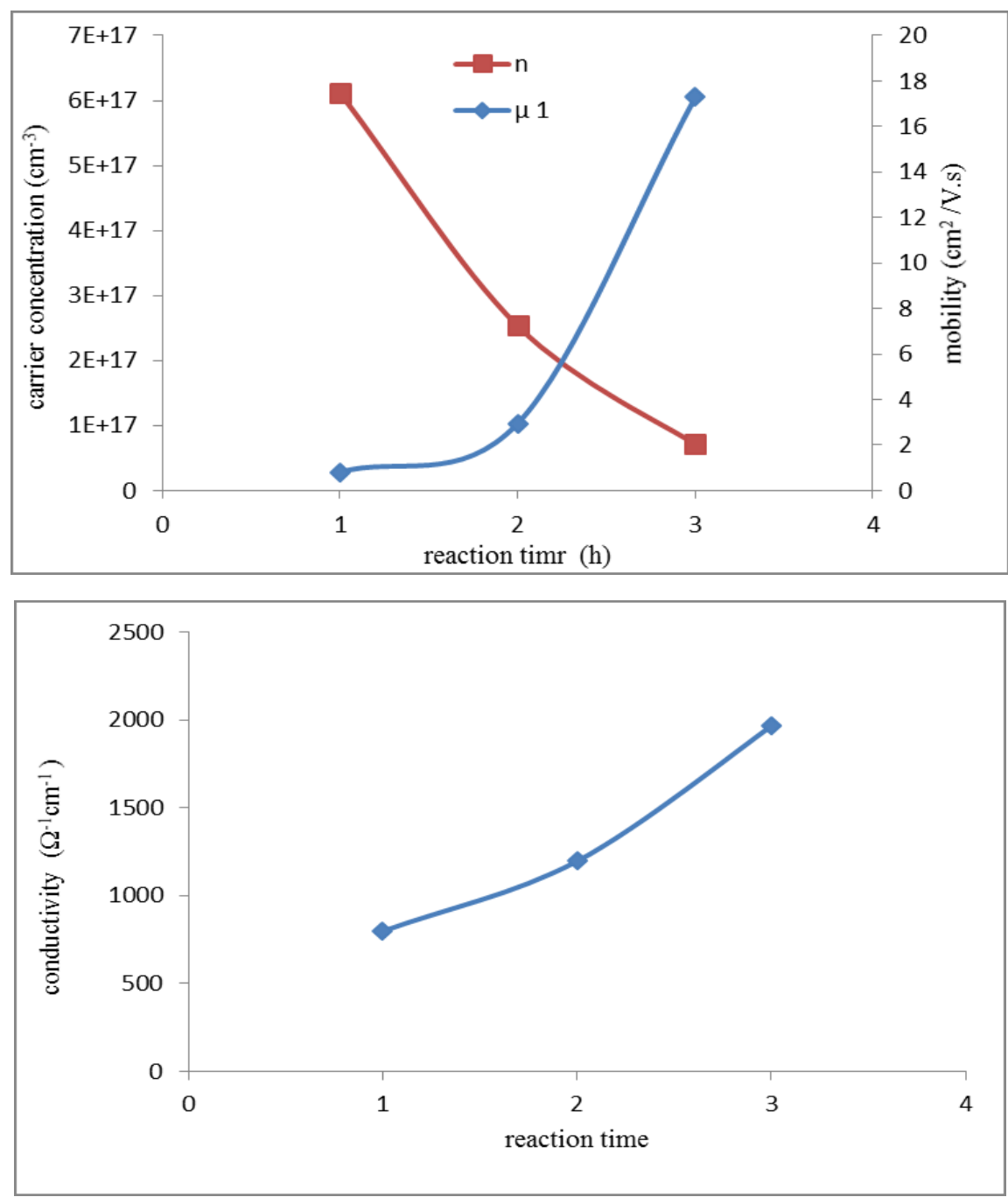

Figure 9: (a) The carrier concentration and mobility of the $1 \% \mathrm{Fe}-\mathrm{TiO}_{2} \mathrm{p}$-type as a function of growth time. (b) The conductivity of the $1 \% \mathrm{Fe}-\mathrm{TiO}_{2}$ at different growth times

Figure 10 displays the effect of growth time on the electric properties of $1 \% \mathrm{Fe}-\mathrm{TiO}_{2}$ prepared by the hydrothermal method. The figure depicts the $\ln \sigma$ vs $1000 / T$ for films with different reaction times at multiple temperatures ranging from $\left(50\right.$ to $\left.125^{\circ} \mathrm{C}\right)$. From the figure, it is clear that for all the samples, the conductivity increases with the temperature, which synthesized at different reaction time. This is an indication of the semiconducting behavior of the films. Moreover, the results of the thermoelectric power confirm that the increment of the electrical conductivity is proportional to the film thickness (reaction time). Remarkably, the activation energy was computed employing the equation [12]:

$$
\sigma=\sigma_{0} \exp \left(\frac{E_{a}}{k_{B} T}\right)
$$

Where $\sigma$ is the medium conductivity, $\sigma_{0}$ is a constant value, $T$ is the absolute temperature, and $k_{B}$ is the well-known Boltzmann constant.

The $E_{a}$ were 991.46, 895.96, and $861.64 \mathrm{meV}$ for the films prepared with 1, 2, and 3 hours, indicating that a slight decreased in the activation energy with increasing reaction time. This decrease inevitably leads to improved film conductivity as shown in Table V. 


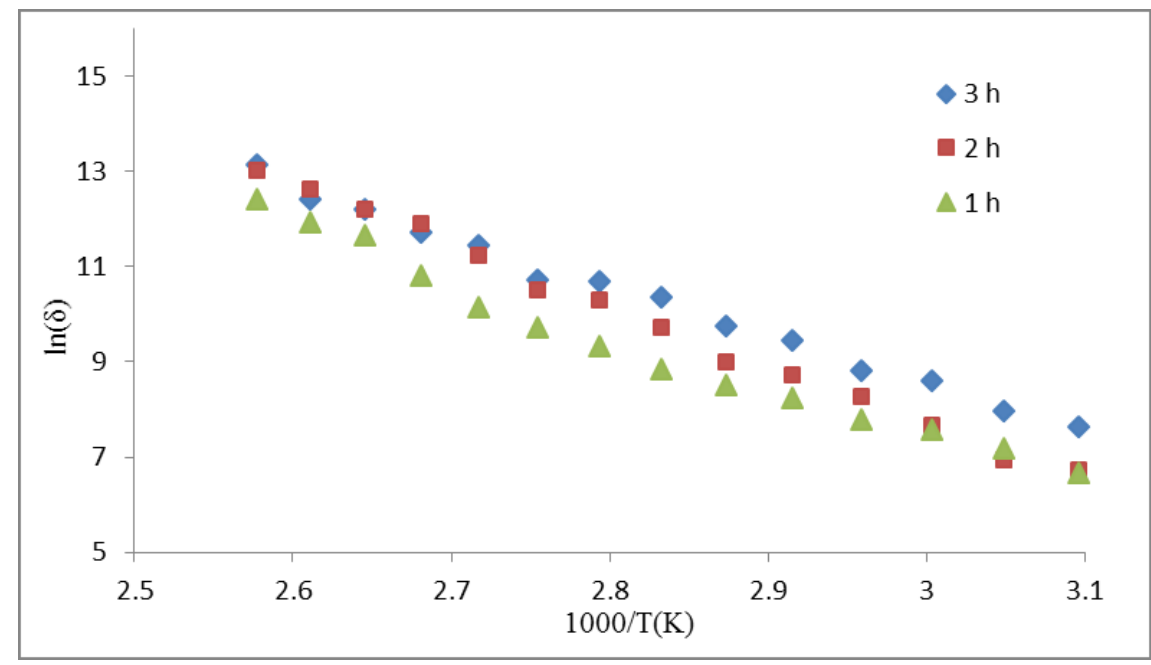

Figure 10: The influence of the aging time on the electric properties of $1 \% \mathrm{Fe}-\mathrm{TiO}_{2} \mathrm{p}$-type from the thermoelectric power measurements. (The legend describes the reaction time in hours)

TABLE V: The activation energy and thickness of the prepared $1 \% \mathrm{Fe}-\mathrm{TiO}_{2}$ films with different reaction times

\begin{tabular}{ccc}
\hline \hline Reaction time (hours) & Film thickness $(\boldsymbol{\mu m})$ & Activation energy $(\mathbf{m e V})$ \\
\hline 1 & 0.87 & 991 \\
2 & 2.4 & 896 \\
3 & 4.1 & 862 \\
\hline
\end{tabular}

\section{Conclusions}

Rutile phase of titanium dioxide with $1 \% \mathrm{Fe}$-dopants can be prepared using simple and low-cost hydrothermal technique. The reaction time has a profound effect on the physical properties of the prepared films. The length of the $\mathrm{TiO}_{2}$ nanorods increased with increasing reaction time from 1 to 3 hours (from 0.87 to $4.1 \mathrm{~nm}$ ), respectively with preferred vertical alignment of the nanorods. The optical energy band gap of the prepared films was found to be decreased from (3.35 to $3.1 \mathrm{eV})$ with increasing preparation time from 1 to 3 hours, respectively. Moreover, such high deposition times can be used to enhance the conductivity, carrier concentration, and mobility of the films.

\section{References}

[1] D. Mardare, M. Tasca, M. Delibas and G. Rusu, "On the structural properties and optical transmittance of $\mathrm{TiO}_{2}$ rf sputtered thin films," Applied Surface Science, 156, 200-206, 2000.

[2] C. Cao, C. Hu, X. Wang, S. Wang, Y. Tian and H. Zhang, "UV sensor based on $\mathrm{TiO}_{2}$ nanorod arrays on FTO thin film," Sensors and Actuators B: Chemical, 156, 114-119, 2011.

[3] C. S. Chou, R.Y. Yang, M.H. Weng and C.H. Yeh, "Preparation of $\mathrm{TiO}_{2} /$ dye composite particles and their applications in dye sensitized solar cell," Powder Technology, 187, 181-189, 2008.

[4] L. Hou, P. Liu, Y. Li and C. Wu, "Enhanced performance in organic light-emitting diodes by sputtering $\mathrm{TiO}_{2}$ ultra-thin film as the hole buffer layer," Thin Solid Films, 517, 4926-4929, 2009.

[5] D. V. Bavykin, V. N. Parmon, A. A. Lapkin and F. C. Walsh, "The effect of hydrothermal conditions on the mesoporous structure of $\mathrm{TiO}_{2}$ nanotubes," Materials Chemistry, 14, 3370 - 3377, 2004.

[6] K. Santhi, M. Navaneethan, S. Harish, S. Ponnusamy and C. Muthamizhchelvan, "Synthesis and characterization of $\mathrm{TiO}_{2}$ nanorods by hydrothermal method with different $\mathrm{pH}$ conditions and their photocatalytic activity,” Applied Surface Science 500, 144058, 2020

[7] S. J. Hashim, O. N. Salman and K. I. Hassoon, "The Optical properties of Fe-Doped $\mathrm{TiO}_{2}$ films prepared by Hydrothermal Technique," Al-Nahrain Journal of Science ANJS, 23(3), 7 - 16, 2020.

[8] Y. Xie, L. Wei, G. Wei, Q. Li, D. Wang, Y. Chen, S. Yan, G. Liu, L. Mei and J. Jiao. "A self-powered UV photodetector based on $\mathrm{TiO}_{2}$ nanorod arrays," Nanoscale Research Letters, 8(1), 188, 2013.

[9] M. Rajabi, and $\mathrm{S}$. Shogh, "Defect study of $\mathrm{TiO}_{2}$ nanorods grown by a hydrothermal method through photoluminescence spectroscopy," Luminescence, 157, 235-242, 2015. 
[10] J. Xi, O. Wiranwetchayan, Q. Zhang, Z. Liang, Y. Sun and G. Cao, "Growth of single-crystalline rutile $\mathrm{TiO}_{2}$ nanorods on fluorine-doped tin oxide glass for organic-inorganic hybrid solar cells," Materials Science: Materials in Electronics, 23(9), 1657-1663, 2012.

[11] S. R. Bera and S. Saha, "Influence of Growth Time in the Formation of CdTe Nanostructure," Nano Vision 6, 1-9, 2016.

[12] L. K. Sudha, R. Sukumar, and K. Uma Rao, "Evaluation of activation energy (Ea) profiles of nanostructured alumina polycarbonate composite insulation materials," International Journal of Materials, Mechanics and Manufacturing, 2(1), 96-100, 2014 